ORIGINAL ARTICLE

\title{
Fracture of the sternum in children
}

\author{
L P Ferguson, A G Wilkinson, T F Beattie
}

Emerg Med J 2003;20:518-520

\begin{abstract}
Objective: Sternal fracture is poorly characterised in children. The purpose of this study was to gain insight into the mechanism, radiological characteristics, and accompanying injuries of sternal fracture in children. Methods: The study was retrospective. The records of all children who underwent plain radiography of the sternum, or computed tomography of the thorax after trauma, over a 40 month period in our paediatric hospital were reviewed for evidence of sternal fracture.

Results: 12 of 33 children identified had radiological evidence of sternal fracture. The age range of children with fractures was 5 to 12 years. Eleven children had fracture of the anterior cortex of the first or second sternebra of the body of the sternum. One child had fracture through the manubriosternal joint with posterior displacement of the body. Seven fractures resulted from direct blows to the anterior chest, five fractures resulted from hyperflexion injury of the thoracic spine. None were the result of motor vehicle crash. All fractures were isolated injuries.

Conclusions: Sternal fracture is uncommon in children. Injury may result from direct or indirect violence. The child's sternum is commonly fractured by more minor blunt trauma than generally recognised in the literature. All patients with sternal fracture after indirect violence should have careful examination of the spine. Patients with undisplaced anterior cortical fracture without other injury may be safely discharged from the emergency department.
\end{abstract}

See end of article for authors' affiliations .....................

Correspondence to: T F Beattie, Royal Hospital for Sick Children, Sciennes Road, Edinburgh EH9 $1 \mathrm{LF}$ Scotland; Lovise.Cowan@ luht.scot.nhs.uk

Accepted for publication 11 December 2002 l $\mathrm{n}$ recent years there has been much interest in the treatment of adults with sternal fracture. ${ }^{12}$ However, in children, fracture of the sternum is an uncommon injury and isolated fracture has been reported on few occasions. ${ }^{3-5}$ The literature suggests that when sternal injury occurs in a child, a particularly forceful blow to the chest has occurred and there is a greater likelihood of intrathoracic injury. ${ }^{6}$ It is widely believed that fractures of the sternum are usually caused by blunt trauma occurring in motor vehicle crashes. ${ }^{7}$ In our anecdotal experience, sternal fracture more often results from more minor trauma and is often an isolated injury. We therefore undertook a review of consecutive cases of sternal injury presenting to our department. Our aim was to study the mechanism, radiological characteristics, and accompanying injuries of sternal fracture in children.

\section{METHODS}

We searched our radiology database to identify children with possible sternal injury presenting to our hospital between July 1998 and October 2001. We included all children who underwent plain radiography of the sternum and all children who had computed tomography of the thorax after trauma. Thirty three patients were identified from the database. The records and radiological reports of all 33 children were reviewed. Twelve children had radiological evidence of sternal injury. All sternal fractures were identified by plain radiography. We looked at the mechanism of injury, sternal fracture pattern, and accompanying injuries in these children. The treatment for the sternal injury was also noted.

\section{RESULTS}

There were four boys and eight girls in age from 5 to 12 years (median 10 years). All 12 patients with sternal fracture had history of trauma (table 1). Seven children had sustained a direct blow to the anterior chest wall-four patients sustained their injuries falling off a bicycle, two patients slipped and fell forwards striking their anterior chest wall. In the remaining five children, sternal injury followed indirect violence after they landed on the upper back or head causing hyperflexion of the thoracic spine. Two patients fell from heights on to their upper back. One fell five feet from a tree and another six feet from a gym bar. Three patients with hyperflexion injury landed awkwardly while bouncing: two on a trampoline, one on a bouncy castle. None of the injuries were the result of a motor vehicle crash.

Eleven of twelve children had an undisplaced fracture of the anterior cortex of the first or second sternebra of the body of the sternum (fig 1). The sternal fracture was an isolated injury from clinical examination in 10 of these children and no further investigations were undertaken. One patient (case 4) had tenderness over the T4 and T5 spinous processes after hyperflexion injury. Neurological examination was normal. Magnetic resonance imaging of the thoracic spine showed no evidence of spine injury and she was discharged. All children with isolated anterior cortical fracture were safely discharged from the emergency department. Five of these children were reviewed up to three weeks after the initial injury at the discretion of the treating physician. All five children were still requiring analgesia and had persistent pain on deep inspiration and movement for several weeks after the injury.

There was one case of displaced sternal fracture that resulted from falling from a bicycle at speed onto a wall (case 1). A lateral sternal radiograph showed complete fracture through the manubriosternal joint with posterior displacement of the body. The chest radiograph was unremarkable for other injury. Echocardiography and 12-lead electrocardiograph were normal. Initially she was managed conservatively with rest and analgesia and the fracture reduced spontaneously into normal alignment overnight. She returned to the department four days after the injury with further pain. Repeat radiography showed re-dislocation and she underwent internal fixation of the manubriosternal joint.

\section{DISCUSSION}

Chest wall injuries causing fracture are uncommon in children. The increased pliability and elasticity of the child's chest wall reduces the susceptibility to fracture. ${ }^{7}$ Consequently most reviews conclude childhood sternal 


\begin{tabular}{|c|c|c|c|c|c|}
\hline $\begin{array}{l}\text { Case } \\
\text { number }\end{array}$ & Age $(y)$ & Sex & Cause of injury & Mechanism & Sternal fracture pattern \\
\hline 1 & 12 & $F$ & Fall from bicycle & Direct & $\begin{array}{l}\text { Displaced fracture through } \\
\text { manubriosternal joint }\end{array}$ \\
\hline 2 & 11 & $\mathrm{~F}$ & Slipped in street & Direct & $\begin{array}{l}\text { First sternebra, anterior cortex, } \\
\text { undisplaced }\end{array}$ \\
\hline 3 & 10 & $\mathrm{~F}$ & Fall from bicycle & Direct & $\begin{array}{l}\text { Second sternebra, anterior cortex, } \\
\text { undisplaced }\end{array}$ \\
\hline 4 & 10 & $\mathrm{~F}$ & Fall on bouncy castle & Indirect & $\begin{array}{l}\text { First sternebra, anterior cortex, } \\
\text { undisplaced }\end{array}$ \\
\hline 5 & 5 & $\mathrm{~F}$ & Fall from trampoline & Direct & $\begin{array}{l}\text { Second sternebra, anterior cortex, } \\
\text { undisplaced }\end{array}$ \\
\hline 6 & 10 & $\mathrm{~F}$ & Fall from bicycle & Direct & $\begin{array}{l}\text { Second sternebra, anterior cortex, } \\
\text { undisplaced }\end{array}$ \\
\hline 7 & 7 & M & Fall 5 feet from tree & Indirect & $\begin{array}{l}\text { First sternebra, anterior cortex, } \\
\text { undisplaced }\end{array}$ \\
\hline 8 & 11 & $\mathrm{~F}$ & Fall from trampoline & Indirect & $\begin{array}{l}\text { Second sternebra, anterior cortex, } \\
\text { undisplaced }\end{array}$ \\
\hline 9 & 10 & M & Fall from trampoline & Indirect & $\begin{array}{l}\text { First sternebra, anterior cortex, } \\
\text { undisplaced }\end{array}$ \\
\hline 10 & 11 & M & Slipped in bath & Direct & $\begin{array}{l}\text { First sternebra, anterior cortex, } \\
\text { undisplaced }\end{array}$ \\
\hline 11 & 11 & M & Fall from bicycle & Direct & $\begin{array}{l}\text { Second sternebra, anterior cortex, } \\
\text { undisplaced }\end{array}$ \\
\hline 12 & 10 & $\mathrm{~F}$ & $\begin{array}{l}\text { Fall six feet from gym } \\
\text { bar }\end{array}$ & Indirect & $\begin{array}{l}\text { Second sternebra, anterior cortex, } \\
\text { undisplaced }\end{array}$ \\
\hline
\end{tabular}

fracture is usually the result of severe blunt trauma, typically motor vehicle crash, and the likelihood of intrathoracic injury is high. ${ }^{67}$ Children are said to be at risk for the development of significant arrhythmias and admission to an intensive care unit has been advocated for children with sternal fracture. ${ }^{6}$ In our series, none of the sternal fractures were attributable to a motor vehicle crash and many were the result of comparatively minor trauma. None of the children studied had intrathoracic injury and all patients with isolated anterior cortical fracture were safely discharged from the emergency department. Although the study fails to identify children with fatal injury who did not undergo investigation, it is probable that most sternal fractures in children are the result of more minor trauma than previously accepted.

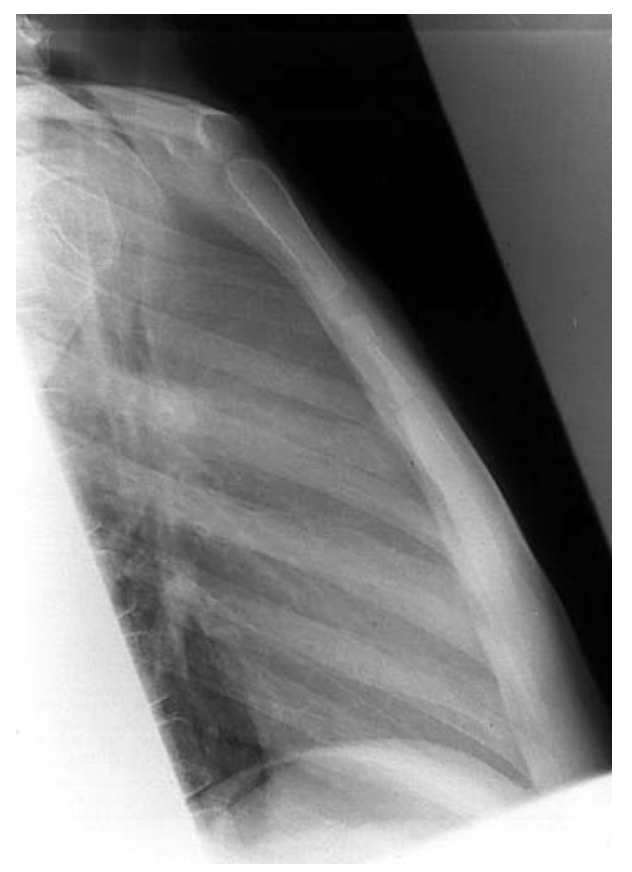

Figure 1 Fracture of anterior cortex of the first sternebra (case 4).
A lateral radiograph of the sternum is usually taken to confirm clinical diagnosis of sternal fracture because displacement and dislocation occur in the sagittal plane. However, interpretation is more difficult in children because the number of ossification centres and their pattern of appearance and fusion vary greatly. ${ }^{8}$ In addition, the synchondrosis between the first and second sternebrae in adolescents may be misinterpreted as a fracture and plain radiography will fail to identify patients with undisplaced transsychondral fractures. ${ }^{6}$ Presumably some of the 21 children with sternal tenderness and pain who were discharged after normal lateral sternal radiography had such fractures. In addition to plain radiography or computed tomography, ultrasound may be used to demonstrate sternal fracture. It is most useful in children who are able to point to the site of tenderness. Ultrasound is less useful in children with diffuse sternal pain.

In adults, two mechanisms of sternal injury have been described. ${ }^{9}$ The first results from direct compression applied to the anterior chest wall or the body of the sternum. The second type follows flexion-compression injury to the upper thorax. We confirmed the same mechanisms of injury are responsible for sternal injury in children. In our study, six of the seven children who sustained direct sternal violence had undisplaced fracture of the anterior cortex of the first or second sternebra. We believe this resulted from a blow to the lower more mobile body causing angulation above the site of impact relative to the fixed manubrium. The sternum becomes angulated slightly beyond its limit of bending and a greenstick fracture is produced. The fracture is an incomplete linear fracture that extends from the convex side of the curvature. The subsequent elastic recoil improves the position. Only one child, the oldest in the series, had a complete fracture with posterior displacement of the body of the sternum. It is likely to have resulted from a direct blow to upper sternum. In adults, direct sternal injuries are often accompanied by rib fractures. However, none of our children with sternal fracture after direct violence had rib fractures on clinical examination, reflecting greater pliability of the chest wall in children.

Flexion-compression injury resulted in fracture of the anterior cortex of the first or second sternebra in five children 
and was indistinguishable radiologically from greenstick fractures after direct violence. Similar radiological features have been reported in other children after flexion-compression injury. ${ }^{3-5}$ This injury pattern contrasts with adults where the most common injury after indirect violence is dislocation or fracture-dislocation of the manubriosternal joint with backward and downward displacement of the manubrium on the body. ${ }^{9}$ Evidence from adult cadaver studies shows that flexion of cervical and thoracic spine from a fall on to the upper part of the spine imparts downward and backward movement to the upper ribs-particularly the upper two ribs. ${ }^{9}$ From the radiological appearances, we assume this force develops in hyperflexion injury in children causing angulation of the sternum similar to that produced by a direct blow to the lower sternum. The fracture that results represents complete failure on the tension side of the bone but only bending on the compression side.

In adults, injury to the sternum after indirect violence is almost always associated with a severe spinal column injury. ${ }^{10}$ None of our cases of flexion-compression injury had spinal injury. However, one patient had spine tenderness and needed further imaging to exclude spinal injury. It is probable that increased flexibility of the spine in children permits the sternum to buckle without spinal injury. Nevertheless thorough clinical examination of the spine is the minimum that should be done to detect spine injury.

\section{Conclusion}

The sternum may be damaged by direct or indirect violence. Sternal fracture is often the result of surprisingly minor trauma and commonly there is no intrathoracic injury. In our experience, by far the commonest sternal injury in children is isolated anterior cortical fracture. These patients were discharged safely from our emergency department without ECG monitoring. Further study is required to identify the role of ECG monitoring in children with sternal injury. All patients with indirect violence should have careful examination of the spine.

\section{Authors' affiliations}

L P Ferguson, T F Beattie, Department of Accident and Emergency Medicine, Royal Hospital for Sick Children, Edinburgh, Scotland A G Wilkinson, Department of Radiology, Royal Hospital for Sick Children

\section{REFERENCES}

1 Sadaba JR, Oswal D, Munsch CM. Management of isolated sternal fractures: determining the risk of blunt cardiac injury. Ann R Coll Surg Engl 2000;82:162-6.

2 Peek GJ, Firmin RK. Isolated sternal fracture: an audit of 10 years' experience. Injury 1995;26:385-8

3 Defriend DE, Franklin K. Isolated sternal fracture-a swing-related injury in two children. Pediatr Radiol 2001;31:200-2.

4 Perez FL Jr, Coddington RC. A fracture of the sternum in a child. J Pediatr Orthop 1983:3:513-15.

5 Perez-Martinez A, Marco-Macian A, Gonzalvez-Pinera J, et al. [Cortical fracture of the sternum in a child: an infrequent case]. Cirugia Pediatrica 1996;9:130-1.

6 Templeton JM. Thoracic trauma. In: Fleisher GR, Ludwig S, eds. Textbook of pediatric emergency medicine. Baltimore: Williams and Wilkins, 1993:1143-66.

7 Gledhill RB. Fractures of the sternum, scapula, and ribs. In: Letts RM, ed. Management of pediatric fractures. New York: Churchill Livingstone, 1994:93-6.

8 Hensinger RN. Development of the sternum. In: Standards in paediatric orthopaedics. New York: Raven Press, 1986.

9 Flowler AW. Flexion-compression injury of the sternum. J Bone Joint Surg 1957;39B:487-97.

10 Gopalakrishnan KC, El Masri WS. Fractures of the sternum associated with spinal injury. J Bone Joint Surg 1986;68B: 178-81. 